\title{
Ecologia de cupins (Insecta: Isoptera) da Amazônia Central: efeitos do desmatamento sobre as populaçōes
}

\author{
Adelmar G. Bandeira $\left[{ }^{*}\right]$
}

\begin{abstract}
Resumo
Foram estudadas a distribuiçâo e diversidade de cupins em áreas de floresta primária, capoeira e pas. tagem na Amazônia Central. Estado do Ainazonas. Foram feitas medidas de umidade do soio, compactaçã do solo (taxa de infiltraçăo de água no solo) e temperaturas do solo e do ar, para estabelecer relaçōes com a distribuiçăo dos cupins. Com um esforço de coletas aproximadamente equivalente nos três ambientes, ficou demonstrado que a maioria dos gêneros se distribui roos três habitats. Nasutitermes foi o gênero mais comum e com maior diversidade, sendo mais freqüente $\mathrm{\epsilon m}$ pastagem. O número total de ninhos de cupins foi também maior na pastagem que na floresta primá. ria. Os cupins do solo podem atingir quase um metro de profundidade e seu número foi maior na capoeira, seguido da pastagem e por último a floresta. A capacidade de infiltraçăo de água no solo e umidade do solo diminuiram com o desmatamento. As flutuações diárias de temperaturas do solo e do ar foram maiores na pastagem que na floresta. A retirada da vegetação primária e as conseqüentes modificaçōes microclimáticas poderiam ter sido responsáveis pela distribuiçăo de certos grupos de Isoptera.
\end{abstract}

\section{IN'TRODUÇÃO}

Os cupins ou térmitas têm uma distribuição geográfica muito ampla, em todas as regiões quentes da terra (Harris, 1961), desde $45^{\circ}-48^{\circ} \mathrm{N}$ a $45^{\circ} \mathrm{S}$ (Wood, 1975 ), ou pelo limite das isotermas anuais de $10^{\circ} \mathrm{C}$ para ambos os hemisférios, mas nos Estados Unidos da América avançam até o limite de $4,4^{\circ} \mathrm{C}$ (Emerson, 1936). Entretanto é nas regiões tropicais que Encontram clima favorável a seu desenvolvimento, sendo também muito importantes na decomposição da matéria orgânica (Matsumoto, 1976) .

Como é conhecido, a distribuição dos seres vivos está estreitamente relacionada com - clima e demais fatores ambientais ou abióticos. Seguindo-se o desmatamento duma área, esses fatores são alterados. Em conseqüên- cia de tais mudanças, algumas espécies de cupins se tornam localmente extintas ou escassas, algumas não são afetadas, ao passo que outras são adversamente atingidas, mas podem reestabelecer-se e aumentar sua atividade (Usher, 1975). É óbvio que o desmatamento tem maior efeito sobre aqueles cupins com sistema de ninhos ligado à vegetação, onde também obtêm alimento, porém esse efeito é maior sobre aqueles que têm constante contato com o solo e que podem, às vezes, ser capazes de construir seu ninho sobre o chão ou subterraneamente (Wood, 1975). Wood acrescenta que a formação de pastagens pode afetar as espécies de cupins tamtém pela exposição ao sol, compactação do solo, presença de fezes e outras influências.

Sands (1965), no Norte da Nigéria, encontrou que a densidade populacional de Trinervitermes obenerianus era mais alta em áreas onde predominava vegetação de gramíneas, ao passo que $T$. auriterrae e $T$. oeconomus eram mais abundantes em locais sombreados de florestas. Em áreas de pastoreio na Austrália, Ferrar \& Watson (1970) encontraram 48 formas (espécies e subespécies) em fezes de animais, sendo que 43 dessas formas foram coletadas em fezes de gado bovino e 20 , em fezes de cavalo.

Fato bastante conhecido e importante é que muitas espécies de cupins constroem seus ninhos de barro (cupinzeiros) sobre o chão $\mathrm{e}$ neste processo os insetos removem partículas de horizontes inferiores para cima do solo, podendo mesmo atingir o subsolo (Hesse, 1955). Além de muitos outros aspectos também importantes da ecologia de cupins, sua predação, segundo vários autores (ex. Harris, 1961; Wood, 1975), ocorre por vários animais, porém as formigas seriam os principais predadores existentes.

(") INPA - Museu Paraense Emilio Goeldi, Belém. 
$\mathrm{Na}$ Amazônia Central, as derrubadas para a formação de pastagens vêm-se ampliando rapidamente (Schubart, 1977; Dantas, 1978). Este trabalho é um estudo do impacto dessas derrubadas sobre a fauna de cupins numa região. Tentou-se estudar a distribuição desses insetos em áreas de pastagens, capoeiras e floresta primária; obter algumas informações sobre sua preferência alimentar por dejetos de animais domésticos; relação com a textura do solo e profundidade de penetração de cupins no solo, através do sistema de ninhos, e, finalmente, algumas observações foram feitas sobre predação por formigas.

Este trabalho é parte duma tese apresentada ao INPA/Universidade do Amazonas, Manaus, defendida em 1978, para obtenção do grau M.Sc., intitulada "Ecologia de térmitas da Amazônia Central : Efeitos do desmatamento sobre as populações e fixação de nitrogênio".

Dedico este trabalho ao $\mathrm{Dr}$. Renato Lion de Araújo, cujo súbito falecimento no dia 7 de setembro de 1978, na cidade do Rio de Janeiro, deixou uma lacuna na Entomologia brasileira. O Dr. Araújo era reconhecidamente o maior especialista em cupins dos últimos anos nas Américas. Além de outras instituições onde também trabalhou, ultimamente realizava pesquisas no Museu de Zoologia da Universidade de São Paulo, onde deixou uma excelente coleção de Isoptera e uma vastíssima bibliografia sobre o mesmo assunto. O Prof. Araújo, além da grande contribuição que deixou à Ciência, era inegavelmente pessoa de personalidade admirável e exemplar. Autêntico e destemido em seu modo de agir e falar e pelo seu grande espírito de brasileirismo, defendia à altura os direitos e ética da ciên. cia e dos cientistas brasileiros.

\section{ÁREA DE ESTUDO}

Esta pesquisa foi realizada na Agropecuária Aruanã, propriedade do Eng. Agr. Sérgio Vergueiro, à altura do $\mathrm{Km} 232$ da rodovia AM-010, que liga Manaus a Itacoatiara (Fig. 1), aproximađamente $3^{\circ} 04^{\prime} \mathrm{S}$ e $58^{\circ} 45^{\prime} \mathrm{W}$, no Município de Silves, Estado do Amazonas, margem esquerda do rio do mesmo nome.
Estudos climatológicos realizados às proximidades de Manaus (Reserva Florestal Ducke) indicam que o clima desta região, segundo a classificação de Köppen, é do tipo Afi, isto é, altas precipitações durante quase todo o ano, com o mês mais pobre em chuvas (setembro) superior a 60 milímetros e o total anual em torno de $2.000 \mathrm{~mm}$; altas temperaturas, com amplitude de suas médias inferior a $5^{\circ} \mathrm{C}$ e a média do mês mais frio nunca inferior a $18^{\circ} \mathrm{C}$ (Ribeiro, 1976). As temperaturas médias mais altas correspondem aos meses de menos chuvas e as mais baixas, aos meses de maior precipitação, porém as temperaturas mínimas sofrem uma ligeira queda nos meses de junho, julho e agosto (meses de pouca chuva), motivadas pelo fenômeno da friagem (Schmidt, 1947).

A vegetação primária é exuberante em sua maior parte. Rodrigues (1967), estudando a mesma região ao longo da rodovia Manaus-Itacoatiara, encontrou uma diversidade média de 65 espécies de plantas por hectare, com o diâmetro mínimo de $25 \mathrm{~cm}$ à altura do peito ou acima da sapopemba e com uma altura média entre 22 e $25 \mathrm{~m}$, com freqüentes árvores emergentes atingindo até $35-40 \mathrm{~m}$ de altura.

A região Manaus-Itacoatiara é de terra firme, embasada sobre sedimentos do Terciário. mais precisamente da formação Barreiras (ou Alter do Chão), que dão origem a solos classificados, em sua maior parte, como Latossolos Amarelos; apresenta vários níveis de terraços, geralmente de pequena extensão, tornando a superficie ondulada; existe também uma relação constante entre os níveis de terraços e c correspondente teor de argila: onde os terraços vão de aproximadamente $6-15 \mathrm{~m}$, o teor de argila varia de $10 \%$ a $35 \%$, constituindo os latossolos das classes texturais leve e média; onde os niveis de terraços variam de $20-50 \mathrm{~m}$. os teores de argila são maiores, podendo superar a $60 \%$ (IPEAN, 1969).

Para realizar este trabalho, foram escolhidos 3 ambientes, com locais de coletas de dados próximos entre si (Fig. 2). Um dos ambientes foi a floresta primária, que em algumas partes já havia sido modificada para a retirada de madeiras de construção. Os outros 2 ambientes foram a pastagem, cuja área já 


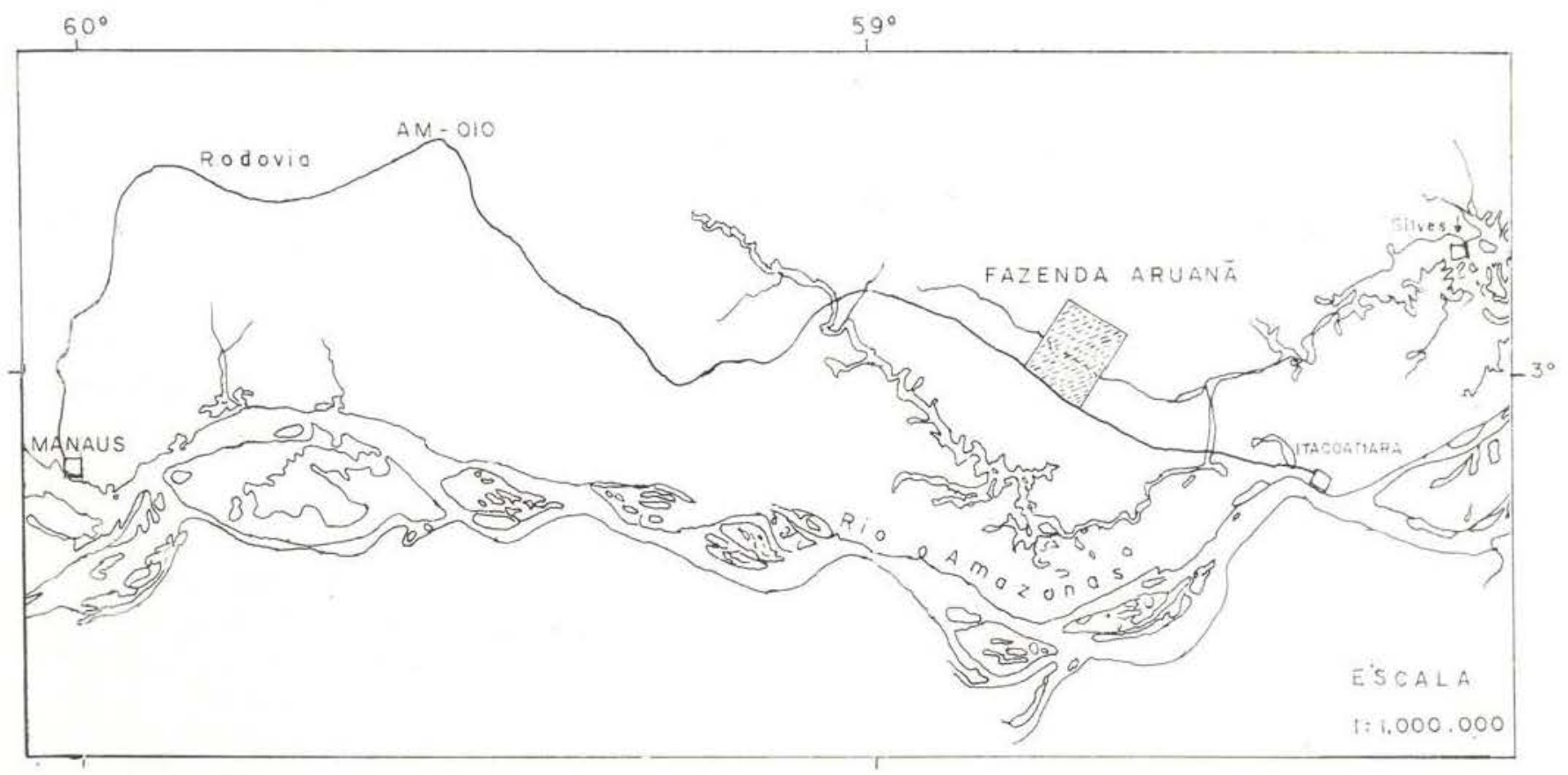

Fig. 1 - Localizaçăo da área de trabalho (Fazenda Aruană).

ultrapassava os 3.000 hectares, e algumas áreas de capoeira. O desflorestamento para formação de pastagens foi iniciado em 1971 e em algumas partes surgiu grande quantidade de plantas invasoras (recolonizadoras), constituindo o que é chamado de capoeira (floresta secundária), sendo que o gado continuiu pastando nessa área. Outro tipo de capoeira que se formou foi uma área em frente à fazenda, desmatada em 1971 para evitar que colonos se estabelecessem às proximidades. Após o primeiro desmatamento, essa área ainda foi roçada e queimada em 1974 e semeado graminea (Panicum maximum), com a qual cresceram plantas invasoras, predominando várias espécies de Solanum (Fam. Solanaceae) e de Cecropia (Fam. Moraceae), mas sem a presença de gado pastando, portanto também sem pisoteio.

\section{Fatores abióticos}

\section{MATERIAIS E MÉTODOS}

Foram considerados três fatores abióti$\cos ^{*}$ umidade do solo, compactação do solo e temperaturas, tanto do solo como do ar. As medidas de umidade e compactação do solo foram feitas em áreas de $625 \mathrm{~m}^{2}(25 \mathrm{~m} \times 25 \mathrm{~m})$ em cada ambiente, relativamente próximas umas das outras (Fig. 2). A pastagem, no local deste experimento, estava com 5 anos, a partir da época do desmatamento, e a capoeira foi a que não sofreu nem pastoreio nem pisoteio de gado, cujo desmatamento havia sido feito há 6 anos.

\section{a) Umidade do solo}

A umidade do solo foi estimada pelo método gravimétrico (Allen, 1974). As amostras, retiradas ao acaso à profundidade de $0 \mathrm{a}$ $5 \mathrm{~cm}$, eram transportadas em sacos plásticos e no laboratório eram colocadas em cadinhos de alumínio, registrado o peso fresco e se secava este solo em estufa a $105^{\circ} \mathrm{C}$ por aproximadamente 2 dias, até o peso ficar estável. Após estar seco, o cadinho com solo era novamente pesado e o valor da umidade era obtido pela fórmula

$$
\text { US }=\frac{\Delta S}{\text { So }} \times 100
$$

Onde : US $=$ umidade do solo; $\Delta S=$ diferença de peso entre o solo úmido e o solo se- 


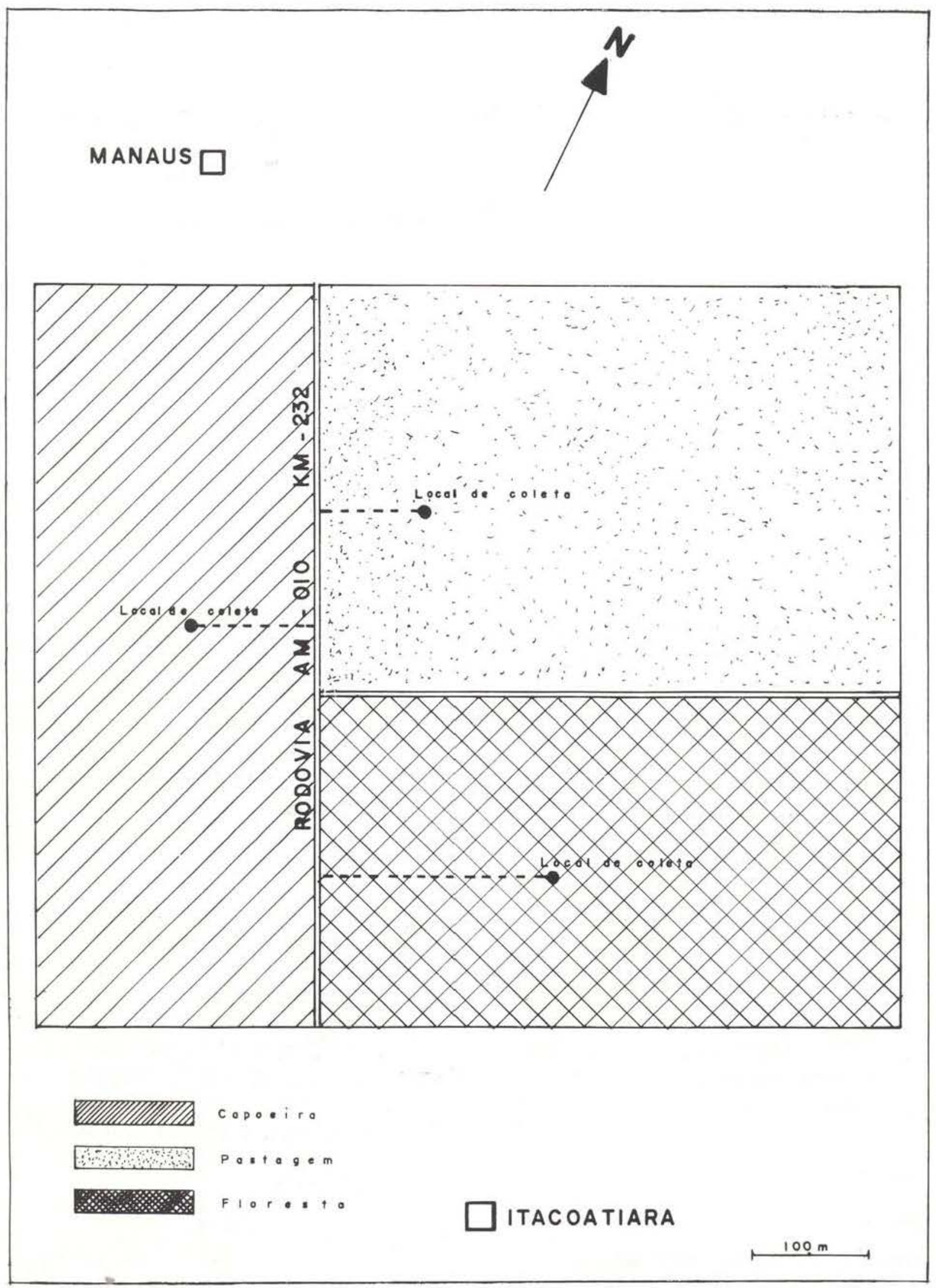

Fig. 2 - Localização dos pontos de coleta de solo para extração de cupins, solo para medir umidade e medidas de infiltração de água no solo. 
co; So $=$ peso do solo úmido. O valor obtido (multiplicado por 100) é a percentagem de água em relação ao peso do solo úmido.

As amostras de solo para umidade foram coletadas de setembro a dezembro de 1977 . em 6 vezes, com intervalos de 6 a 8 dias de uma para outra. De cada vez eram coletadas 5 amostras em cada ambiente, perfazendo o total de 30 na floresta, 30 na capoeira e 30 na pastagem.

\section{b) Compactação do solo}

A compactação foi estimada através de medidas de infiltração de água no solo. Também foram feitas de setembro a novembro de 1977, nos mesmos dias em que foram tiradas amostras de solo para medir a umidade, com um total de 30 medidas em cada ambiente.

Com pontos tomados ao acaso, as medidas de infiltração eram feitas usando-se uma sonda de ferro galvanizado de $10 \mathrm{~cm}$ de altura, paredes de um pouco menos de $1 \mathrm{~mm}$ de espessura, extremidade superior dobrada, formando um arco de resistência, e a extremidade inferior mais afiada, cortante. A sonda, que tinha a área de abertura de $60 \mathrm{~cm}^{2}$, era introduzida no solo até a metade $(5 \mathrm{~cm})$ e a outra parte era destinada a receber água. A quantidade de água usada era 1,0 litro, e para medí-la era usado um recipiente de plástico transparente, graduado em decilitros e em centilitros. Com um cronômetro à mão, registrava-se o tempo gasto para a água penetrar no solo. Quando o solo era muito compacto, a tal ponto que a água demorasse muito para entrar, o procedimento era parar aos 10 minu. tos e anotar quantos $\mathrm{ml}$ de água haviam penetrado. Este método é uma modificação dos tradicionais usados em Hidrologia e tem a fi. nalidade de medir a taxa inicial de infiltração de água, o que é importante para se estimar a capacidade do solo reter a precipitaçâo e já foi usado por Schubart (1977). Para transfor mar os dados em $\mathrm{mm} / \mathrm{min}$, foi empregada a fórmula

$$
V I=\frac{V}{S} \times \frac{1}{t} \times 600
$$

Onde : VI = velocidade de infiltração de água; $V^{\prime}=$ volume de água que penetrou $\left(\mathrm{em}^{\mathrm{cm}}\right)^{3}$; $\mathrm{S}=$ área do infiltrômetro $\left(60 \mathrm{~cm}^{2}\right) ; \mathrm{t}=$ tem. po em segundos. Como se vê, $\mathrm{V} / \mathrm{S}=\mathrm{cm}^{3} /$ $\mathrm{cm}^{2}=\mathrm{cm}$; o tempo na fórmula é seg; portanto, o resultado daria $\mathrm{cm} / \mathrm{seg}$ e não $\mathrm{mm} / \mathrm{min}$. Para se transformar em $\mathrm{mm} / \mathrm{min}$, basta multiplicar o resultado obtido por 600 , isto é, 10 $(1 \mathrm{~cm}=10 \mathrm{~mm}) \times 60(1 \mathrm{~min}=60 \mathrm{seg})$.

Foram retiradas amostras de solo compostas no interior dos quadrados dos 3 ambientes, na profundidade de 0 a $10 \mathrm{~cm}$ e a análise granulométrica foi feita no laboratório da Se. çăo de Solos do CPATU (EMBRAPA), em Belém, supervisionada pelo $\mathrm{Dr}$. I. C. Falesi.

\section{c) Temperaturas do solo e do ar}

As temperaturas foram medidas no solo às profundidades de $0 \mathrm{~cm}, 5 \mathrm{~cm}$ e $10 \mathrm{~cm}$ e no ar à altura de $150 \mathrm{~cm}$, somente na pastagem e na floresta. Nos primeiros dias, as medidas foram feitas de hora em hora, durante o dia e toda a noite; posteriormente só foram feitas medidas das 7 às 20 horas, e eram feitas com pares termoelétricos de fios de cobre-constantan, com junta fria em banho de gelo, sombreados, para evitar a incidência direta do sol, e acoplados a um Millivolt Potentiometer modelo 8690-2 (da Leeds \& Northrup I nc.-USA), cujos dados foram transformados em temperaturas $\mathrm{em}{ }^{\circ} \mathrm{C}$ usando a tabela do aparelho. Os termopares eram ligados ao potenciômetro através de um fio telefônico de grande extensão, permitindo que as medidas fossem feitas praticamente ao mesmo tempo na floresta $e$ na pastagem, com exceção das primeiras medidas, que foram feitas em dias diferentes em cada ambiente. Este experimento foi realizado em colaboração com o Sr. Mário Dantas.

resultados

\section{a) Umidade do solo}

Os dados de umidade do solo são apresen. iados na Tabela 1, sob a forma de percentagens de água no solo em relação ao peso fres- 
co. As médias (globais) foram comparadas estatisticamente. Para fazê-lo, verificou-se que os dados não eram normais, simétricos. Usando o teste de Bartlertt, transformando-se os dados em seus logarítimos, estes se normalizaram, mas as variâncias permaneceram diferentes. Neste caso, teve-se que usar a teste F's aproximado de igualdade de médias, quando as variâncias são heterogêneas (Sokal 8. Rohlf, 1969: 372-73), mostrando que as médias são difertntes. Usando-se um teste nãoparamétrico para múltiplas comparaçōes (Zar. 1974: 156-57), ficou demonstrado diferença significativa a nível de $\mathrm{P}<0,01$.

TABELA 1 - Umidade do solo: percentagens de água em relação ao peso do solo fresco. $(\bar{X}=$ média parcial, de 5 medições; $\bar{X}=$ média global; $S=$ desvio padrăo da média, e $\mathrm{N}=$ número de unidades de amostras por ambiente). As médias globais $(\bar{X})$ sāo signicativamente diferentes a nível de $\mathrm{P}<0,01$.

\begin{tabular}{cccc}
\hline $\begin{array}{c}\text { DATA } \\
(1977)\end{array}$ & $\begin{array}{r}\text { FLORESTA } \\
\overline{\mathrm{X}} \pm \mathrm{S}\end{array}$ & $\begin{array}{r}\text { CAPOEIRA } \\
\overline{\mathrm{X}} \pm \mathrm{S}\end{array}$ & $\begin{array}{r}\text { PASTAGEM } \\
\overline{\mathrm{X}} \pm \mathrm{S}\end{array}$ \\
\hline $30 . \mathrm{X}$ & $29,3 \pm 1,9$ & $27,2 \pm 1,9$ & $25,3 \pm 2,5$ \\
$08 . \mathrm{X}$ & $30,4 \pm 2,2$ & $27,9 \pm 5,2$ & $26,8 \pm 2,7$ \\
$14 . \mathrm{X}$ & $28,2 \pm 1,2$ & $23,5 \pm 1,5$ & $22,2 \pm 1,4$ \\
$22 . \mathrm{X}$ & $29,7 \pm 1,3$ & $28,2 \pm 3,2$ & $23,3 \pm 2,1$ \\
$29 . \mathrm{X}$ & $29,4 \pm 1,7$ & $28,0 \pm 1,8$ & $23,1 \pm 1,0$ \\
$04 . \mathrm{XI}$ & $29,7 \pm 2,7$ & $24,0 \pm 1,8$ & $23,4 \pm 2,0$ \\
\hline $\bar{X} \pm \mathrm{S}$ & $29,4 \pm 1,9$ & $26,5 \pm 3,3$ & $23,9 \pm 2,5$ \\
$\mathrm{~N}$ & 30 & 30 & 30 \\
\hline
\end{tabular}

O solo da pastagem sempre foi o mais seco de todos, de setembro a dezembro de 1977 . até mesmo quando as amostras foram retiradas após chover, porém nesse período houve relativamente pouca precipitação. A capoeira apresentou umidade intermediária, o que mostra que ela é proporcional à cobertura vegetal, porém com maiores flutuações, até mesmo que na pastagem, como o mostram os desvios padrões (globais e parciais), o que significa que a cobertura vegetal tem importante efeito sobre a umidade do solo. O fato das variações serem maiores na capoeira que na pastagem deve estar relacionado com a maior heterogeneidade da cobertura da capoeira. Apesar de tudo, as variações detectadas, para determinado ambiente, não parecem ter mag. nitude apreciável. Teriam sim, se comparado um ambiente com os outros.

\section{b) Compactação do solo}

As medidas de infiltração de água no solo são dadas em mm/min (Tab. 2). Assim como a umidade, a infiltração mostrou-se diretamente relacionada com a cobertura vegetal. Aqui os desvios padrões são muito grandes, indicando acentuada heterogeneidade entre as medidas, isto é, há locais onde o solo é muito compacto, principalmente na pastagem, e outros onde há mais porosidade. Foi verifificado algumas vezes na pastagem que, onde a água se infiltrava mais rapidamente, havia cupins no solo. Outras vezes o acréscimo na infiltração era simplesmente devido à presença de buracos ou fendas no terreno.

TABELA 2 - Infiltração de água no solo. $(\bar{X}=$ média parcial, de 5 mediçōes; $\bar{X}=$ média global; $S=$ des. vio padrão da média, e $\mathrm{N}=$ número total de medidas). As medidas são dadas em $\mathrm{mm} / \mathrm{min}$, e as médias globais são significativamente diferentes a nivel de $P<0,01$

\begin{tabular}{cccr}
\hline $\begin{array}{c}\text { DATA } \\
\text { (1977) }\end{array}$ & $\begin{array}{r}\text { FLORESTA } \\
\bar{X} \pm \mathrm{S}\end{array}$ & $\begin{array}{r}\text { CAPOEIRA } \\
\overline{\mathrm{X}} \pm \mathrm{S}\end{array}$ & $\begin{array}{r}\text { PASTAGEM } \\
\overline{\mathrm{X}} \pm \mathrm{S}\end{array}$ \\
\hline $30 . \mathrm{IX}$ & $114,8 \pm 83,6$ & $380,8 \pm 182,6$ & $75,7 \pm 49,9$ \\
$08 . \mathrm{X}$ & $624,0 \pm 177,9$ & $197,0 \pm 62,3$ & $103,9 \pm 169,3$ \\
$14 . \mathrm{X}$ & $394,0 \pm 345,0$ & $363,5 \pm 261,4$ & $77,9 \pm 87,5$ \\
$22 . \mathrm{X}$ & $645,1 \pm 385,2$ & $175,0 \pm 63,3$ & $290,5 \pm 204,7$ \\
$29 . \mathrm{X}$ & $337,1 \pm 91,3$ & $262,6 \pm 107,1$ & $73,2 \pm 48,9$ \\
$04 . \mathrm{XI}$ & $610,6 \pm 199,7$ & $311,8 \pm 233,8$ & $21,1 \pm 17,3$ \\
\hline $\bar{X} \pm \mathrm{S}$ & $459,3 \pm 289,5$ & $281,8 \pm 174,7$ & $107,1 \pm 138,2$ \\
$\mathrm{~N}$ & 30 & 30 & 30 \\
\hline
\end{tabular}

Os dados foram analisados estatisticamente. Como se apresentassem condições semelhantes às análises feitas para umidade, foram então usados os mesmos testes, e as médias globais foram significativamente diferentes a nivel de $\mathrm{P}<0,01$.

Segundo Villela \& Mattos (1975: 71-72), a infiltração de água no solo decresce, quando aumenta a umidade. Com os dados do pre. sente trabalho foi tentada correlação entre a 
umidade e a infiltração, tomadas as medidas parciais, isto é, de cada vez que se ia ao campo (Fig. 3), mas parece que os dados são poucos, uma vez que os desvios padrões já mostram grande heterogeneidade da porosidade do solo nos respectivos habitats (Tab. 2). Portanto não é possível tirar conclusões precisas de tal fato.

A análise granulométrica mostra que o solo da área estudada, nos 3 quadrados, é muito semelhante quando à textura (Tab. 3) e que é do tipo latossolo amarelo textura muito argilosa.

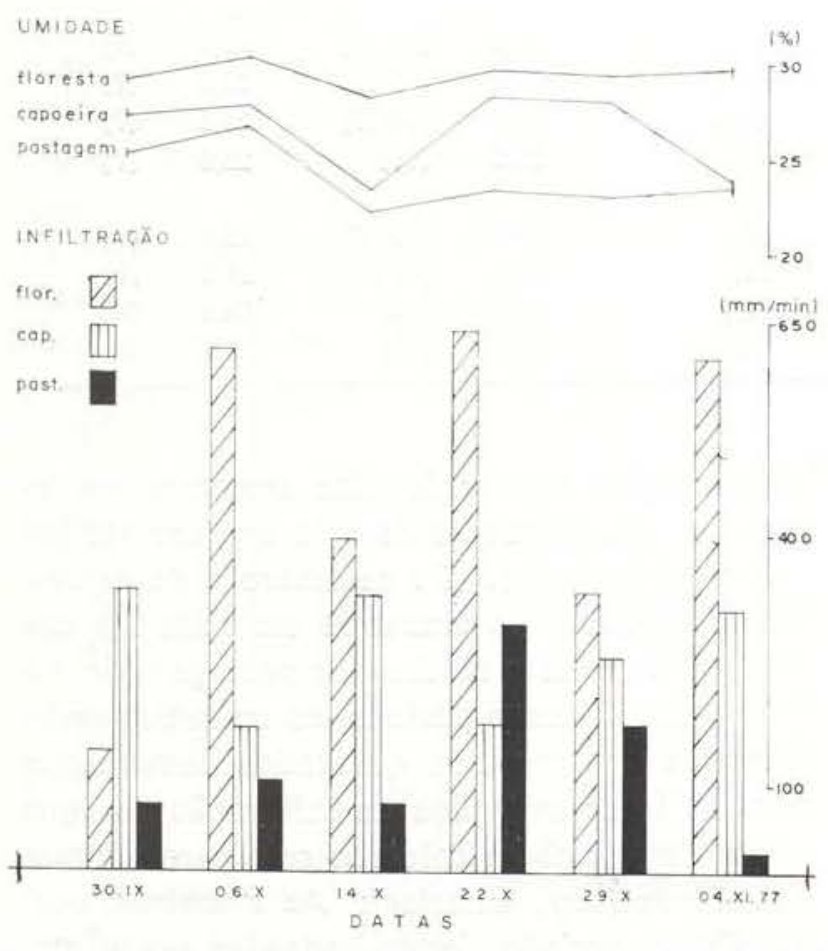

Fig. 3 - Umidade e infiltração de água no solo, medidas de $0.5 \mathrm{~cm}$ de profundidade. em 3 habitats.

TABELA 3 - Granulometria do solo na área de estudo (resultado em percentagem).

\begin{tabular}{lcccc}
\hline AMBIENTE & $\begin{array}{c}\text { AREIA } \\
\text { GROSSA }\end{array}$ & $\begin{array}{c}\text { AREIA } \\
\text { FINA }\end{array}$ & LIMO & $\begin{array}{c}\text { ARGILA } \\
\text { TOTAL }\end{array}$ \\
\hline Floresta & 7 & 2 & 19 & 72 \\
Capoeira & 7 & 2 & 21 & 70 \\
Pastagem & 7 & 3 & 18 & 72 \\
\hline
\end{tabular}

Ecologia de...

\section{c) Temperaturas do solo e do ar}

As medidas de temperaturas, da fioresta e da pastagem, estão representadas na tabela 4 , mas somente as máximas e mínimas. Os resultados mostram-se bastante dependentes do ambiente, variando mais onde havia pouca vegetação. Vê-se que as máximas da pastagem foram sempre superiores e as mínimas às vezes inferiores às da floresta. Nas profundidades maiores do solo, a temperatura é relativamente constante. A superfície geralmente é mais quente durante o dia e mais fria à noite que as camadas inferiores.

Segundo Garcia \& Becker (1975), a faixa de temperatura em laboratório na qual colonias iniciantes de Nasutitermes nigriceps podem desenvolver-se é bastante limitada, variando entre $26^{\circ}$ a mais ou menos $32^{\circ} \mathrm{C}$, ficando o ótimo em volta de $29^{\circ}$ a $30^{\circ} 3$. Pelos dados do presente trabalho, pode-se ver que na pastagem muitas vezes a temperatura ascende a valores bem superiores ao limite encontrado para o desenvolvimento de $N$. nigriceps, tendo sido registrada uma temperatura de $57,5^{\circ} \mathrm{C}$ à superfície do solo num dia de poucas nuvens. Nos demais dias em que foram feitas medidas, o céu estava nublado, tendo até chovido algumas vezes.

TIPOS DE VEGETAÇÄO E SUA FAUNA DE CUPINS MATERIAIS E MÉTODOS

Os cupins foram coletados em vários locais diferentes, tais como cupinzeiros sobre o chão, em ninhos nas árvores, no solo livre, em fezes de gado, etc. Para coletá-los, os ninhos eram parcialmente destruídos com enxada ou terçado para expor os insetos, e com uma pinça eram pegos os maiores ou de mandibulas muito cortantes e os menores, mais frágeis, eram pegos com pincel. Os cupins do solo foram extraídos pelo método de Berlese-Tullgren (Macfadyen, 1953), cujo funil do aparelho era de fibra de vidro, com $14,5 \mathrm{~cm}$ de diâmetro na boca, lâmpada de 15 watts à distância de $14 \mathrm{~cm}$ sobre o funil. As amostras de solo eram retiradas com uma sonda metá. lica simples, de $5 \mathrm{~cm}$ de altura e $9,6 \mathrm{~cm}$ de diâ- 
TABELA 4 - Temperaturas $\left({ }^{\circ} \mathrm{C}\right)$ do solo, às profundidades de $0 \mathrm{~cm}, 5 \mathrm{~cm}$ e $10 \mathrm{~cm}$, e do ar, à altura de $150 \mathrm{~cm}$.

\begin{tabular}{|c|c|c|c|c|c|c|c|c|c|c|}
\hline \multirow[b]{2}{*}{ DATA } & \multirow{2}{*}{\multicolumn{2}{|c|}{ PROF. / ALT. }} & \multicolumn{4}{|c|}{ PASTAGEM } & \multicolumn{4}{|c|}{ FLORESTA } \\
\hline & & & MAX. & (HORA) & MIN. & (HORA) & MAX & (HORA) & MIN. & [HORA] \\
\hline \multirow[t]{4}{*}{ 31.VIII-1.IX.77 } & 5 & & 57,5 & (13) & 22,0 & (6) & \multirow{2}{*}{\multicolumn{4}{|c|}{... }} \\
\hline & 0 & & 39,0 & $(14)$ & 24,0 & $(6)$ & & & & \\
\hline & 10 & & 34,5 & $(14-15)$ & 26,0 & $(4-6)$ & & & & \\
\hline & 0 & & & & & & 37,5 & (11) & 19,5 & (6) \\
\hline \multirow[t]{3}{*}{ 01-02.IX.77 } & 5 & & \multicolumn{4}{|c|}{$\cdots$} & 31,0 & (20?) & 20,0 & (6) \\
\hline & 10 & & & & & & 31,0 & (20?) & 20,5 & (6) \\
\hline & 0 & & 35,5 & (12) & 22,0 & (7) & 28,0 & $(14-15)$ & 24,0 & $(7-8,3-6)$ \\
\hline \multirow[t]{4}{*}{$28-29 . \times .77$} & 5 & & 31,0 & $(14-16)$ & 22,5 & (7) & 25,0 & $(11,15-16)$ & 24,0 & $(7-8)$ \\
\hline & 10 & & 30,0 & (15) & 22,0 & (7) & 26,0 & $(11-12)$ & 24,0 & (7) \\
\hline & & 150 & 34,0 & (14) & 22,0 & (7) & 30,0 & (14) & 23,0 & (7) \\
\hline & 0 & & 30,5 & (14) & 23,5 & (7) & 26,5 & $(15-17)$ & 22,0 & (7) \\
\hline \multirow[t]{4}{*}{ 18.XI.77 } & 5 & & 29,5 & $(11-12)$ & 24,0 & $(7-8)$ & 26,0 & $(15-17)$ & 22,5 & (7) \\
\hline & 10 & & 28,0 & $(11-17)$ & 24,0 & $(7-8)$ & 25,5 & $(15-17)$ & 23,5 & (7) \\
\hline & & 150 & 34,0 & (11) & 22,5 & (7) & 28,5 & (11) & 22,0 & (7) \\
\hline & 0 & & 30,0 & $(12-13)$ & 24,0 & (9) & 28,0 & $(15-16)$ & 23,5 & (9) \\
\hline \multirow[t]{3}{*}{ 29.XI.77 } & 5 & & 29,0 & (13-15) & 24,0 & (9) & 26,5 & $(16-17)$ & 24.0 & (9) \\
\hline & 10 & & 28,0 & $(13-17)$ & 24,0 & (9) & 26,5 & (16) & 24,0 & (9) \\
\hline & & 150 & 36,0 & (15) & 23,0 & (9) & 30,5 & (15) & 23,0 & (9) \\
\hline
\end{tabular}

metro; o solo era transportado em sacos plásticos para o laboratório e o tempo entre a coleta e a deposição no aparelho nunca excedeu 24 horas. O líquido usado para extração em aparelho de Berlese-Tullgren era formol a $1 \%$. Após essa extração, o material era triado e os cupins eram conservados em álcool a $80 \%$, assim como os que eram coletados dos ni. nhos e outras estruturas.

Inicialmente o inventário - não incluindo os cupins do solo - foi feito na pastagem, usando-se o tempo de 4 dias de trabalho integral. A fim de se poder verificar a distribuição dos cupins nas diferentes formações vegetais, foram feitas coletas também duran. te quatro dias na capoeira e quatro na floresta.

De maio a agosto, 10 amostras de solo eram retiradas por mês em cada ambiente, para extração de cupins, com intervalos de um mês de uma para outra, (total de 40 amostras por ambiente), mas sem ter sido estabelecido um local definido para as mesmas, sendo que na pastagem eram coletadas amostras em locais de solo arenoso e de solo argiloso (40 em cada tipo de solo). De setembro a dezembro, foram coletadas 90 amostras em cada um dos ambientes, exceto na área de pastagem de solo arenoso. Nesse período, as amostras eram retiradas nos mesmos quadrados demarcados para se fazer medições de infiltração de água e onde era também coletado solo para estimar a umidade (cap. anterior). As amostras, nesse último período, foram retiradas em 9 etapas, sendo 10 amostras de cada vez, com intervalos de 6 a 8 dias de uma para outra, com exceção das três últimas, que tiveram intervalos maiores, de até 22 dias.

$\mathrm{Na}$ pastagem, é possível que as coletas representem grande parte da comunidade de cupins, pois era bem mais fácil a localização dos ninhos, devido a escassa vegetaçāo. Na capoeira, havia mais arbustos e vários deles continham espinhos. Na mata, a maior dificuldade para se conseguir uma boa amostragem era que os ninhos se localizavam muito distante uns dos outros. 
Os Isoptera foram identificados somente a gênero pelo $\mathrm{Dr}$. Renato L. Araújo, no Museu de Zoologia da Universidade de São Paulo. onde está depositada parte do material, e o restante dividido entre o INPA e o Museu Paraense Emilio Goeldi. Posteriormente os cupins serão estudados a nivel de espécies.

Para se ter uma idéia da diversidade de cupins na área, alguns gêneros, principalmente os mais comuns, foram separados em morfo-espécies.

\section{RESULTADOS}

Foram encontrados representantes das 3 familias de cupins mais comuns no Brasil. A maior diversidade e maior quantidade de individuos coletados são pertencentes à família Termitidae. Em segundo lugar ficou a família Rhinotermitidae e em terceiro a Kalotermitidae, esta com apenas uma amostra, constituída somente de ninfas. O resultado global é o seguinte (autor e data segundo Araujo, 1977) :

Termitidae

Apicotermitinae

Grigiotermes Mathews, 1977 e Ruptitermes Mathews, 1977.

Nasutitermitinae

Armitermes Wasmann, 1897; Constrictotermes Holmgren, 1910; Cornitermes Wasmann. 1897; Labiotermes Holmgren, 1912; Nasutitermes Dudley, 1890; Subulitermes Holmgren, 1910 e Syntermes Holmgren, 1910.

\section{Termitinae}

Amitermes Silvestri, 1901; Cavitermes Emerson, 1925; Cornicapritermes Emerson. 1950; Genuotermes Emerson, 1950; Microcerotermes Silvestri, 1901; Neocapritermes Holmgren, 1912; Orthognathotermes Holmgren, 1910; Spinitermes Wasmann, 1897 e Termes Linnaeus, 1758.

Rhinotermitidae

Coptotermitinae

Coptotermes Wasmann, 1896.

Heterotermitinae

Heterotermes Frogatt, 1896.

\section{Rhinotermitinae}

Rhinotermes Hagen, 1858.

Kalotermitidae (somente ninfas e não foi possível a identificação) .

A fim de se ter uma idéia da distribuição dos cupins entre os 3 ambientes de sua diversidade de hábitos, os gêneros dos isópteros são organizados em tabelas. Na Tabela 5 €stão representados os cupins da familia Termitidae. Para cada gênero é dado um resumo das condições em que os insetos se encontravam no momento em que foram coletados, isto é, da moradia. É muito provável que os locais de coletas correspondam às fontes de alimentos, principalmente quando os cupins eram coletados no interior de troncos de ma. deira em decomposiçăo, fezes de animais e assim por diante. Nos casos em que os insetos foram simplesmente coletados num ninho de barro numa árvore, por exemplo, é aufícil para se dizer qual seria a alimentaçäo dos mesmos, pois dali eles podem se dirigir a 10cais diversos, através de galerias e às vezes perambulam por locais desprotegidos, como foi observado em Constrictotermes.

Na Tabela 6 estãu os 3 gêneros da família Rhinotermitidae e um exempiar da familia Kalotermitidae, mostrando inclusive que há uma variedade grande de hábitos nos rinotermitídeos, apesar de haver poucas espécies coletadas de cada um dos gêneros dessa familia.

Os gêneros Nasutitermes, Cornitermes, Neocapritermes e Syntermes foram separados em morfo-espécies. Nasutitermes foi o gênero de maior diversidade, com aproximadamente 30 espécies. Os 3 outros gênero apresentaram diversidade bem inferior: 4 espécies de Cornitermes, 4 de Neocapritermes e 2 de Syntermes. Das 30 espécies de Nasutitermes, 16 foram encontradas na pastagem, $13 \mathrm{na}$ capoeira e 10 na floresta. Isto não quer dizer que a diversidade seja menor na floresta; é que nesse habitat os ninhos se encontravam muito distantes uns dos outros, ao contrário das áreas mais abertas, onde os ninhos estavam mais concentrados, facilitando a coleta.

Os Syntermes parecem ser muito importantes na decomposição da folhagem. Por aigumas vezes estes cupins foram observados cortando folhas secas, que são carregadas pa- 
TABELA 5 - Distribuiçăo e locais de coletas dos gêneros de cupins da familia Termitidae.

\begin{tabular}{|c|c|}
\hline GENEROS & FLORESTA \\
\hline Armitermes & $\begin{array}{l}\text { ninho de barro no chão; no } \\
\text { solo }\end{array}$ \\
\hline Cornitermes & $\begin{array}{l}\text { ninho de barro no chão na } \\
\text { base duma árvore viva. }\end{array}$ \\
\hline Grigiotermes & $\begin{array}{l}\text { ninho de barro na base de } \\
\text { árvore viva; no solo. }\end{array}$ \\
\hline Labiotermes & $\begin{array}{l}\text { ninho de barro em (sobre) } \\
\text { árvore. }\end{array}$ \\
\hline Nasutitermes & $\begin{array}{l}\text { ninho de matéria org. }{ }^{*} \text { em } \\
\text { árvore viva; interior tronco } \\
\text { em decomposição; galerias } \\
\text { em árvores vivas e mortas; } \\
\text { em estoque de madeira pa- } \\
\text { ra cerca. }\end{array}$ \\
\hline
\end{tabular}

Syntermes

Termes

Microcerotermes

Genuotermes

Ruptitermes

Cavitermes

Constrictotermes

Cornicapritermes

Amitermes

Neocapritermes

Subulitermes

Spinitermes

Orthognathotermes ninho de barro no chão; solo.

ninho em árvore viva; sob casca de árvore recentemente caída (morta)

ninho de barro + mat. org. (?) em árvore viva.

ninho de barro em árvore viva.

no solo.

ninho de barro na base duma árvore viva.

ninho de barro em árvore viva.

no solo.

(n)

ninho de barro na base duma árvore morta; no solo $0^{*}$.

ninho de barro no chão, na base dum toco, interior tronco em decomposiçâo.

no solo.

ninho de barro na base de árvore viva.

ninho em árvore viva, em árvore morta, sobre toco interior tronco em decomposição: galerias sobre o solo.

ninho de barro no chão; solo.

ninho de mat. org. na base dum toco; no solo.

galerias em árvore viva; andando sobre árvore caida.

$\begin{array}{ll} & \text { ninho de } \\ \ldots & \text { toco. }\end{array}$

ninho de barro em volta de árvores; galerias de barro em esteio de cerca.

ninho de barro na base de árvore viva; ninho em árvore morta; ninho sobre o solo; interior tronco em decomposição.

ninho de barro no chão, no solo; interior tronco em decomposição .

ninho de barro na base dum toco.
PASTAGEM

ninho de barro na base dum toco: em fezes bovinas.

ninho de barro no chão: na base dum toco; interior tronco em decomposiçāo.

ninho de barro na base dum toco: em fezes bovinas; no solo.

ninho de barro no chão.

ninho em árvore morta; sobre toco, sobre esteio de cerca; galerias sobre o solo: interior tronco em decomposição: fezes bovinas $e$ eqüinas.

ninho de barro no châo; solo.

ninho de barro na base dum toco, progredindo para dentro.

no solo.

ninho de barro sobre toco (erivolvencio-o); galerias de barro em árvore morta.

ninho de barro na base árvore viva; base de toco: interior tronco em decomposiçāo .

ninho de barro na base de toco; no solo; interior tronco em decomposição.

ninho de barro na base dum toco.

(*) - Solo $=$ solo + liteira.

(*) - Todos os ninhos de Nasutitermes eram de matério orgânica. 
TABELA 6 - Distribuição e locais de coletas dos cupins das familias Rhinotermitidae (Coptotermes, Heterotermes e Rhinotermes) e Kalotermitidae.

\begin{tabular}{|c|c|c|c|}
\hline GENEROS & FLORESTA & CAPOEIRA & PASTAGEM \\
\hline Coptotermes & $\begin{array}{l}\text { ninho de barro na base de } \\
\text { árvore morta; interior tron- } \\
\text { co em decomposição. }\end{array}$ & $\begin{array}{l}\text { interior de árvore morta; } \\
\text { em fezes bovinas. }\end{array}$ & $\begin{array}{l}\text { interior de toco tronco e } \\
\text { raiz exposta em decomposi- } \\
\text { ção. }\end{array}$ \\
\hline Heterotermes & $\begin{array}{l}\text { interior de tronco em de- } \\
\text { composição; no solo }+ \text { li- } \\
\text { teira. }\end{array}$ & $\begin{array}{l}\text { interior de tronco em de- } \\
\text { composição; no solo }+ \text { li- } \\
\text { teira. }\end{array}$ & $\begin{array}{l}\text { interior de tronco em de- } \\
\text { composição; em fezes eqüi- } \\
\text { nas e bovinas; no solo + } \\
\text { liteira. }\end{array}$ \\
\hline Rhinotermes & $\cdots$ & $\cdots$ & $\begin{array}{l}\text { interior de tronco em de- } \\
\text { composição. }\end{array}$ \\
\hline $\begin{array}{c}\text { Kalotermitidae } \\
\text { (gênero ?) }\end{array}$ & $\cdots$ & $\cdots$ & $\begin{array}{l}\text { interior tronco em decom- } \\
\text { posição, não muito úmido. }\end{array}$ \\
\hline
\end{tabular}

ra seus ninhos, geralmente subterrâneos, mas também podendo ser cupinzeiros sobre o solo. Apesar da preferência destes cupins pelas folhas secas, algumas vezes eles trituravam também folhas esverdeadas, recentemente caidas. Mesmo buscando alimento em locais totalmente desprotegidos, sem galerias, tais cupins geralmente não são atacados por predadores, exceto por uma espécie de formiga Ponerinae - Pachycondyla (= Termitopone) comutata.

Os demais gêneros de Isoptera não foram subdivididos, mas a maioria deles também é representada por mais de uma espécie, parecendo que somente alguns são representados por uma única espécie.

$\mathrm{Na}$ Tabela 7 estão agrupados os 21 gêneros de Isoptera coletados na Agropecuária Aruanã. Com um tempo de esforço semelhante despendido para as coletas, vê-se que foi também semelhante a diversidade, a nivel apenas de gêneros, de cupins em cada habitat. Porém é de se esperar que a diversidade na floresta seja maior que a dos outros biótopos, pois ao fim do período de 4 dias de investigacoões ainda estavam aparecendo cupins de "espécies" diferentes nesse ambiente.

No primeiro período de coletas de cupins do solo - de maio a agosto - verificou-se que havia pouquíssimos isópteros na área de pastagem arenosa, parecendo estar relaciona- do com a textura pedológica. Na floresta tam. bém não foram encontrados muitos cupins nesse período (Tab. 8, primeira parte). Verifi. cada a grande diferença em relação ao tipo

TABELA 7 - Distribuiçâo global dos 21 gêneros de cupins coletados na Agropecuária Aruană $(+=$ pre. sença de cupins).

\begin{tabular}{lccc}
\hline GENERO & FLORESTA & CAPOEIRA & PASTAGEM \\
\hline 01 Armitermes & + & + & + \\
02 Coptotermes & + & + & + \\
03 Cornitermes & + & + & + \\
04 Grigiotermes & + & + & + \\
05 Heterotermes & + & + & + \\
06 Labiotermes & + & + & + \\
07 Nasutitermes & + & + & + \\
08 Syntermes & + & + & + \\
09 Termes & + & + & + \\
10 Microcerotermes & + & + & $\ldots$ \\
11 Genuotermes & + & $\ldots$ & + \\
12 Ruptitermes & + & $\ldots$ & + \\
13 Cavitermes & + & $\ldots$ & $\ldots$ \\
14 Constrictotermes & + & $\ldots$ & $\ldots$ \\
15 Cornicapritermes & + & $\ldots$ & $\ldots$ \\
16 Amitermes & $\ldots$ & + & + \\
17 Neocapritermes & $\ldots$ & + & + \\
18 Subulitermes & $\ldots$ & $\ldots$ & + \\
19 Spinitermes & $\ldots$ & $\ldots$ & + \\
20 Orthognathotermes & $\ldots$ & $\ldots$ & + \\
21 Rhinotermes & $\ldots$ & $\ldots$ & + \\
\hline TOTAL P/ HABITAT & 15 & 14 & + \\
\hline & & & + \\
\hline
\end{tabular}


TABELA 8 - Número de cupins por $\mathrm{m}^{2}$ do solo até $5 \mathrm{~cm}$ de profundidade, incluindo a folhagem, extraída pelo método de Berlese-Tullgren, em dois períodos distintos de maio a agosto e de setembro a dezembro de 1977 ( $\mathrm{N}=$ número de amostras do solo).

\begin{tabular}{lrccc}
\hline & \multicolumn{4}{c}{ CUPINS $/ \mathrm{m}^{2}$} \\
\cline { 2 - 5 } AMBIENTE & MAI-AGO & $\mathrm{N}$ & SET-DEZ & $\mathrm{N}$ \\
\hline Floresta (1) & 3,4 & 40 & 453,1 & 90 \\
Capoeira (1) & $1.109,3$ & 40 & 708,6 & 90 \\
Pastagem (1) & 219,4 & 40 & 620,8 & 90 \\
Pastagem (2) & 17,3 & 40 & $\ldots$ & $\ldots$ \\
\hline
\end{tabular}

(1) - Solo argiloso, tipo latossolo amarelo.

(2) - Solo arenoso, bostante leve.

de solo, foi que se resolveu retirar as amostras dentro dos mesmos quadrados onde seriam feitas as medidas de infiltração de água no solo e de umidade do solo.

A vegetaçẫo da Amazônia Central é do ìpo sempre-verde, mas há um período do ano em que as chuvas diminuem e há a queda de uma maior quantidade de folhas. Klinge \& Rodrigues (1968) coletaram liteira durante dois anos (1963 e 1964) numa floresta de terra firme, próximo a Manaus, e verificaram que $50 \%$ da queda das folhas se dá de julho a outubro. sendo que há períodos mais ou menos curtos em que há verdadeiros picos na produção de detritos, podendo variar de ano para ano. Esses autores observaram no primeiro ano uma produção total de manta vegetal de 7,9 toneladas/ha/ano (peso seco), e no segundo ano, de 6,7 toneladas/ha/ano.
No ano de 1977, quando foram feitas as investigaçōes para o presente trabalho, a queda das folhas, pelo menos na área de estudo, deu-se na grande maioria de agosto a setembro. Por coincidência, em setembro, quando se resolveu demarcar uma área em cada arnbiente para se fazerem as coletas de dados. inclusive de solo para extração de isópteros, surpreendentemente começaram a aparecer cupins nessa época (início em 30 de setembro), havendo uma maior quantidade de insetos no solo (solo + liteira) no início, na floresta, e diminuindo progressivamente mais para o fim do ano (Fig. 4), quando a liteira também diminuía. Na pastagem parece que houve um aumento em outubro e na capoeira ocorreu o semelhante em novembro. Os dados globais em cupins por $\mathrm{m}^{2}$, deste segundo periodo, estão na segunda parte da Tabela $8 \mathrm{e}$ na Tabela 9. Tanto no primeiro quanto no segundo período, houve maior número de insetos por unidade de área na capoeira e em segundo lugar, na pastagem. Na floresta encontraram-se menos cupins no solo, durante o primeiro e segundo períodos da realização deste trabalho. As populaçōes ou ninhos de cupins têm uma distribuição contagiante, a nível de 0,05 (índice de Morisita), o que não constituı surpresa, pois os insetos são sociais. A ordem crescente da agregação entre os habitats é a seguinte : Floresta - pastagem — capoeira.

Alguns cupins, pertencentes às duas principais famílias, foram encontrados alimentando-se de fezes bovinas e eqüinas (Tab. 10).

TABELA 9 - Cupins do solo, extraídos pelo método de Berlese-Tullgren, de 90 amostras em cada ambiente. $(\mathrm{N}=$ número de cupins por gênero; $\%=$ percentagem de determinado gênero, e $n=$ número de amostras com cupins).

\begin{tabular}{|c|c|c|c|c|c|c|c|c|c|}
\hline \multirow{2}{*}{ GENEROS } & \multicolumn{3}{|c|}{ FLORESTA } & \multicolumn{3}{|c|}{ CAPOEIRA } & \multicolumn{3}{|c|}{ PASTAGEM } \\
\hline & $\mathrm{N}$ & $\%$ & $\mathrm{n}$ & $\mathrm{N}$ & $\%$ & $\mathrm{n}$ & $\mathrm{N}$ & $\%$ & $n$ \\
\hline Armitermes & 14 & 4,9 & 2 & 141 & 30,6 & 2 & 0 & 0,0 & 0 \\
\hline Cornicapritermes & 3 & 1,0 & 1 & 0 & 0.0 & 0 & 0 & 0,0 & 0 \\
\hline Grigiotermes & 236 & 82,8 & 13 & 207 & 45,0 & 8 & 187 & 50,1 & 12 \\
\hline Heterotermes & 25 & 8,8 & 2 & 70 & 15,2 & 7 & 50 & 13,4 & 7 \\
\hline Ruptitermes & 7 & 2,5 & 1 & 0 & 0,0 & 0 & 18 & 4,8 & 2 \\
\hline Subulitermes & 0 & 0,0 & 0 & 4 & 0.9 & 1 & 118 & 31,6 & 3 \\
\hline Termes & 0 & 0,0 & 0 & 38 & 8.3 & 1 & 0 & 0,0 & 0 \\
\hline TOTAL & 285 & 100,0 & 18 & 460 & 100,0 & 19 & 373 & 99,9 & 21 \\
\hline
\end{tabular}




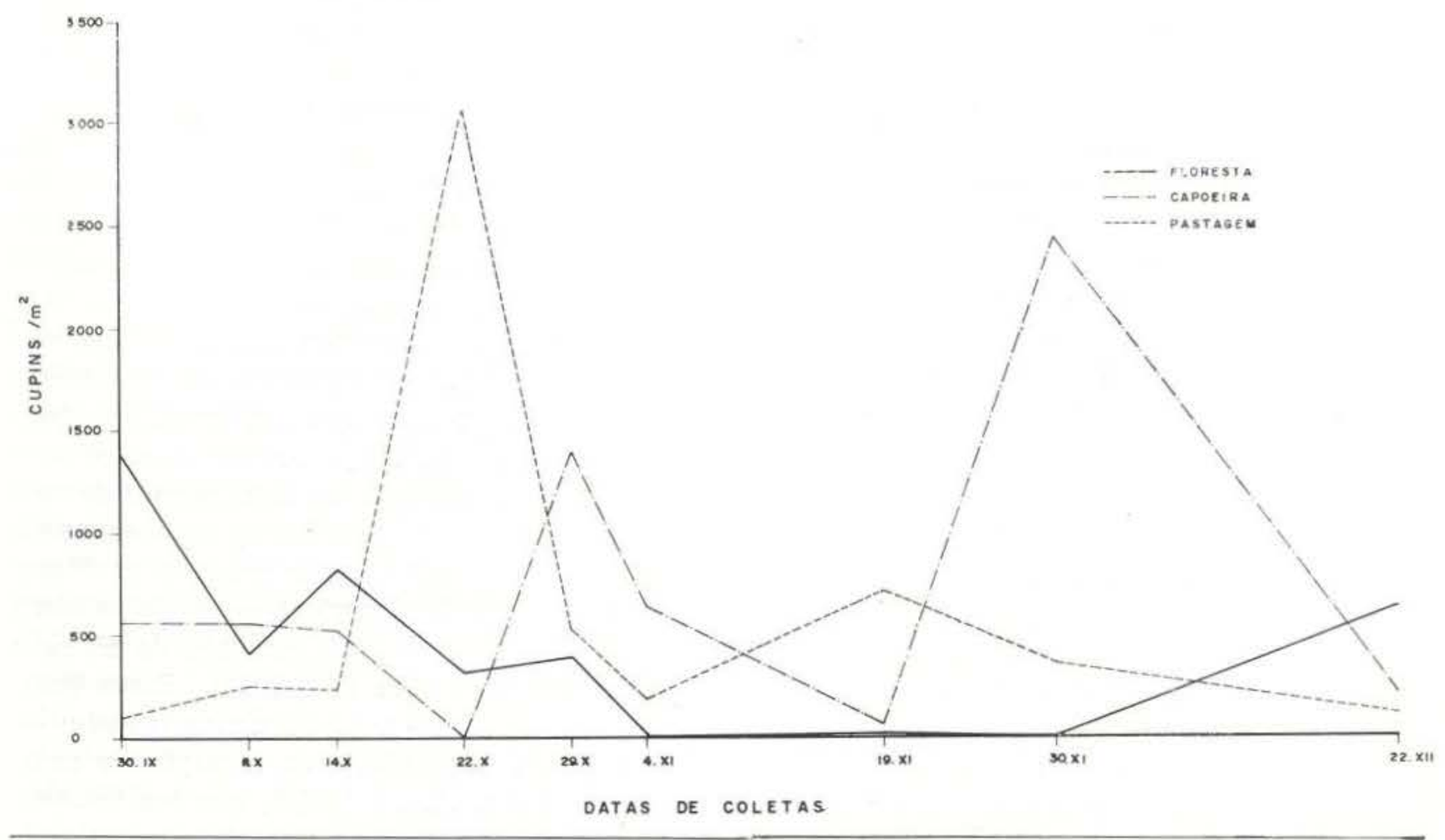

Fig. 4 - Número de cupins por $\mathrm{m}^{2}$ do solo até $5 \mathrm{~cm}$ de profundidade, extraídos pelo método de Berlese-Tullgren, de setembro a dezembro de 1977.

TABELA 10 - Lista de cupins encontrados em fezes de gado, bovino e eqüino, na pastagem.

\begin{tabular}{ccc}
\hline \multicolumn{1}{c}{ ESPECIES } & FEZES BOVINAS & FEZES EQUINAS \\
\hline Heterotermes sp. & + & + \\
Nasutitermes sp. 11 & + & + \\
Grigiotermes sp. & + & - \\
Armitermes sp. & + & - \\
Coptotermes sp. & + & - \\
\hline
\end{tabular}

Dos 5 gêneros de hábitos coprófagos, somente 2 foram encontrados em fezes eqüinas, ao passo que todos foram encontrados em fezes bovinas, mas isso pode ser devido à maior quantidade de gado vacum na fazenda, em relação a. gado cavalar. Tentou-se obter a percentagem de fezes contendo cupins e é bem inferior a $1 \%$. Também só foram encontradas fezes com cupins em locais de solo bastante argiloso.
RELAÇÕES ENTRE CUPINS E SOLO

\section{MATERIAIS E MÉTODOS}

$\mathrm{Na}$ pastagem foram escolhidos 10 cupinzeiros de tamanho médio para serem escavados. De início eram medidos a altura, o diâmetro maior e o diâmetro transversal ao diâmetro maior. Cavava-se o cupinzeiro com uma enxada, cuidadosamente, para observar a presença dos cupins, que eram coletados para identificação, e outros animais associados. Media-se a profundidade até onde eram encontrados os cupins e a profundidade do cupinzeiro mesmo, isto é, até onde havia galerias feitas pelos insetos e onde o barro era mais friável, talvez pela concentração da matéria orgânica, tornando-se menos pegajoso à ferramenta, em comparação com o solo adjacente. A área era de solo argiloso (latossolo amarelo pesado).

Foi feita também contagem de ninhos habitados por cupins, no chão e arborícolas, na pastagem e em floresta primária, tanto em lo- 
cais de solo argiloso quanto em solo arenoso. Para contar os ninhos, era estendida uma fita de 50 metros de extensão num local cuja direção havia sido determinada ao acaso. Era considerada como área de amostragem a faixa compreendida entre 5 metros de cada lado da fita. Os ninhos eram então contados separando-se os do chão dos arborícolas, numa extensão total de 250 metros em cada ambiente, isto é, floresta de solo arenoso e de solo argiloso e pastagem de solos arenoso e argiloso.

\section{RESULTADOS}

As dimensões dos 10 cupinzeiros escavados na pastagem estão representadas na Tabela 11. Em quase todos os cupinzeiros não foram encontrados insetos no limite inferior do ninho, isto é, no limite da profundidade do cupinzeiro mesmo. A profundidade maior, na qual havia cupins no momento, foi de $76 \mathrm{~cm}$, e a profundidade máxima do cupinzeiro em si foi de 90 centímetros. De um modo geral, os cupins estavam mais concentrados na parte do ninho que ficava mais um menos à altura do horizonte superior do solo, no topo do terreno. No interior dos cupinzeiros foram encontrados também vários termitófilos, tais como formigas, grilos, besouros, lagartos, sapos, minhocas, etc. As coletas de cupins dos cupin-

TABELA 11 - Dimensões em $\mathrm{cm}$ de 10 cupinzeiros escavados na pastagem. Média dos diâmetros $=$ média entre o diâmetro maior e o transversal a este; profundidade com cupim $=$ (até onde foram vistos cupins).

MEEDIA
CUPINZEIRO ALTURA DOS
DIÁMETROS C/CUPINS CUPINZEIROS

\begin{tabular}{rrrrr}
\hline 1 & 40 & 75 & 76 & 76 \\
2 & 45 & 125 & 35 & 45 \\
3 & 23 & 118 & 30 & 90 \\
4 & 30 & 120 & 22 & 55 \\
5 & 66 & 130 & 27 & 50 \\
6 & 28 & 75 & 15 & 41 \\
7 & 37 & 69 & 21 & 53 \\
8 & 55 & 150 & 27 & 44 \\
9 & 48 & 108 & 22 & 56 \\
10 & 63 & 79 & 30 & 43 \\
\hline
\end{tabular}

zeiros escavados se perderam, razão por que năo se pode fornecer os dados na íntegra, mas a maioria era Armitermes, sendo que havia também Syntermes e outro(s).

A atividade de cupins, no Oeste da Malá sia, estende-se desde $40 \mathrm{~m}$ de altura, sobre as grandes árvores, até $1 \mathrm{~m}$ de profundidade do solo (Matsumoto, 1976). Na Amazônia Central, parece acontecer fato idêntico. Dos 10 cupinzeiros escavados, que não eram dos maiores, 1 deles mediu $90 \mathrm{~cm}$ de profundidade; então é possível que um termiteiro mais ou menos grande atinja $1 \mathrm{~m}$ ou mais de profundidade de remoção de solo, apesar de não se ter visto termiteiros muito grandes nesta região, como acontece por exemplo no Maranhão - Leste da Amazônia - , onde existem ninhos de Syntermes sp. com $3 \mathrm{~m}$ de altura e um diâmetro na base de até $8 \mathrm{~m}$. Esses grandes cupinzeiros - e os pequenos também têm grande importância na remoção do solo, pois, segundo Hesse (1955), que fez estudos tísicos e químicos com material de cupinzeiros no Leste da África, os cupins utilizam o subsolo para construir seus ninhos.

A contagem dos ninhos habitados por cupins revelou que há diferenças tanto em relação ao tipo de solo como também o tipo de vegetação (Tab. 12). Pode-se verificar que em áreas de solo arenoso, tanto na pastagem quanto na floresta, há menos ninhos que em

TABELA 12 - Número de cupinzeiros por hectare. Fo. rom feitas contagens na floresta primária e na pastagem, numa parcela de 5 anos, ambos os ambientes com partes de solo arenoso e de solo argiloso, sendo considerados separadamente cada tipo de solo. Tam. bém os ninhos arborícolas foram separados dos termiteiros do chão.

\begin{tabular}{|c|c|c|c|}
\hline \multirow{2}{*}{ AMBIENTE } & \multicolumn{2}{|c|}{ POSIC̣ÃO DO CUPINZEIRO } & \multirow{2}{*}{ TOTAL } \\
\hline & ARBORICOLA & NO CHĀO & \\
\hline Flor. solo arenoso & 26.7 & 3.3 .3 & 60,0 \\
\hline Flor. solo argiloso & 36,0 & 64,0 & 100,0 \\
\hline Past. solo arenoso & 13,3 & 6,7 & 20,0 \\
\hline Past. solo argiloso & 52,0 & 152,0 & 204,0 \\
\hline
\end{tabular}


habitats semelhantes de solo argiloso. Em áreas de solo de textura leve, o número de termiteiros diminuiu com a formação da pas tagem, enquanto que onde a textura do solo é argilosa, o número de cupinzeiros aumentou depois de formada a pastagem, em relação floresta primária. Essa última parte confirma o que foi verificado na extração de cupins do solo, pelo método de Berlese-Tullgren, em solo argiloso de floresta e pastagem: na pas. tagem havia mais insetos por unidade de área que na floresta.

$O$ experimento do presente trabalho mostra que o número de cupinzeiros em geral aumentou após a formação da pastagem, mas somente em áreas de solo argiloso, e principalmente dos cupinzeiros construídos no chão. $\mathrm{Na}$ mata primária de solo de textura leve, existem menos ninhos que na mata de solo argiloso, e, após a formação da pastagem, o número de termiteiros diminuiu ainda mais (ao contrário de onde o solo é argiloso).

O crescimento das populações de cupins do solo livre (cap. anterior) e do número de termiteiros na pastagem poderia ser explicado pela modificação do efeito predatório por formigas, o que Bodot (1967) sugere como possível fator que afeta a distribuição de cupins em savanas da Costa do Marfim. Neste experimento, foram encontrados menos cupins na pastagem de solo arenoso que onde o solo é argiloso, conforme citado acima, porém no material extraído do solo arenoso livre havia muito mais formigas que no material do solo argiloso. Neste caso as formigas, embora não se saiba se eram todas predadoras de cupins, poderiam ser um dos fatores importantes na redução da densidade dos isópteros na pastagem arenosa, além da influência direta do solo sobre estes insetos.

Lee \& Wood (1971) afirmam que não existem estimativas confiáveis de populações de cupins em nenhum habitat. Este experimento da escavação e contagem de cupinzeiros mostra que realmente é muito difícil obter-se a densidade destes insetos, pois, além de serem necessários blocos de solo de grandes profundidades para a extração total dos cupins, a textura pedológica também exerce apreciável influência sobre a densidade dos isópte- ros. Porém essa considerável penetração tem grande importância na formação e aeração do solo, favorescendo inclusive a retenção de água e o crescimentó das raizes dos vegetais.

\section{FORMIGAS PREDADORAS DE CUPINS}

\section{MATERIAIS E MÉTODOS}

Durante o inventário dos cupins na Agropecuária Aruanã, quando os ninhos eram parcialmente destruídos para serem feitas as coletas, formigas de várias espécies se aproximavam para predar os então indefesos isópteros. Visto a frequeência com que o fato ocorria e a grande importância que representa pa. ra o ecossistema, algumas formigas foram também coletadas, mas somente as que eram vistas pegando ou carregando cupins. Elas eram pegas com pinça e colocadas em frascos contendo álcool a $80 \%$, semelhante ao que se fazia com os cupins. Algumas vezes esperava-se aproximadamente meia hora para que se aproximasse maior número de formigas, permitindo também que mais espécies se fizessem presentes. O material foi identificado pelos Drs. Cincinato Gonçalves, N. Penny e W. Overal e ficará na coleção entomológica do Museu Paraense Emílio Goeldi.

\section{RESULTADOS}

As formigas observadas predando cupins foram Azteca sp., Camponotus sp., Comomyr. ma pyramica, Crematogaster sp., Ectatomma quadridens, Gigantiops destructor, Pachycondyla crassinoda (vista somente carregando um cupin morto do gênero Syntermes), Pheidole sp., Pseudomyrmex sp., Solenopsis (do grupo saevissima), Pachycondyla (= Termitopone) comutata e Ecitonini (gênero não identificado) . Ao todo, essas formigas representam talvez mais de 15 espécies, pois alguns dos gêneros acima citados contêm 2 ou mais espécies.

Observou-se que parece não haver especificidade de predação entre formigas e cupins - qualquer formiga predadora, quase sem exceções, pode matar qualquer cupim, até mesmo quando há desproporção em tamanho. Uma das formigas que parece predar somen- 
de um grupo de Isoptera é Pachycondyla comutata (Ponerinae). Segundo Wheeler (1936), talvez esta seja a formiga mais especializada, que preda apenas cupins do gênero Syniermes, o que realmente foi observado durante a presente pesquisa. No entanto, outras formigas podem se aproveitar dos cupins já mortos, ou apenas imobilizados, por $P$. comutata e carregarem-nos para seus ninhos. Isto possivelmente foi o que aconteceu com $P$. crassinoda, que foi vista com um operário de Syntermes, porém nunca foi vista atacando cupins vivos. Wheeler afirma também que a distribuição de $P$. comutata parece estar estreitamente relacionada com a distribuição dos Syntermes apenas na América do Sul, principalmente do Trópico de Capricórnio para o Norte. Algumas vezes foram observadas até 4 espécies de formigas predando cupins duma única espécie, quando seu ninho era aberto. As formigas apresentam preferência pelos operários de cupins, mas predam também soldados, mesmo que estes tenham substâncias de defesa.

Certa vez foi observado um combate entre 2 espécies de Nasutitermes (Nas. sp. 24 e Nas. sp. 26). Os cupins da espécie número 24 saíam do seu ninho, situado sobre um toco, $\epsilon$ atacavam os da outra espécie, cujo ninho era situado numa árvore de Solanum a 1,60 m de altura, parcialmente destruído. A luta se dava principalmente entre os operários, e os cupins do ninho da árvore, que eram menores, perdiam na luta, sendo jogados ao chão quase mortos, ou mesmo mortos. Formigas de várias espécies aproveitavam dos cupins imobilizados e os carregavam. Também várias moscas pousavam sobre os cupins mortos, parecendo estarem fazendo ovipostura. A quantidade de cupins no chão era tão grande que parecia atingir centenas de milhares de insetos.

Após 20 dias, voltando-se ao local, já não havia mais nenhum cupim no ninho. No seu lugar havia formigas do gênero Crematogaster, que podem ser predadoras. Passados 4 meses e 18 dias, novamente voltando lá para observar, já uma outra espécie de Nasutiter. mes, Nas. sp. 02, estava ocupando o ninho. Este fato sugere, inclusive, que um estudo da arquitetura de ninhos de Nasutitermes, e tal- vez de outros cupins, seja em parte dificultada pela sucessão dos ocupantes, pois da primeira vista não se pode dizer qual foi real. mente o que construiu determinado ninho. E um mesmo ninho, possivelmente, teria partes construídas por uma espécie e outras partes por outra(s) espécie(s) diferente(s).

\section{DISCUSSÃO E CONCLUSÕES}

Os fatores abióticos aqui estudados apresentaram características muito diversas, mostrando estar relacionados com a cobertura vegetal. A umidade e infiltração de água no solo ficaram reduzidas onde a floresta foi removida. A diminuição da umidade seria em parte uma conseqüência da compactação do solo, mas também por causa do maior poder de evaporação devido aos ventos, que, segundo Longman \& Jeník (1974), são um dos fatores ecológicos mais importantes na evaporação, e são mais intensos em áreas de pouca vegetação. Os ventos sendo menos intensos na floresta, essa pode conservar umidade relativa do ar mais alta e com menos variações, e isso seria semelhante para o solo. Um outro fator que poderia acelerar a evaporação de água do solo é a quantidade de radiação solar, que é mais intensa sobre o solo menos protegido de vegetação.

A taxa de infiltração de água no solo reduzida significa compactação do solo. Em ćreas de pastoreio, um dos fatores importantes na compactação é o pisoteio do gado (Wood, 1975). Isso traria como conseqüência, entre outras, o aumento do "run-off" da água das chuvas, que, ao invés de se infiltrar no solo e se depositar no lençol d'água subterrâneo, para posteriormente alimentar o sistema fluvial e lacustre, escorre imediatamente para es igarapés e rios. Se considerarmos as áreas de pastoreios e de culturas rasteiras cada vez mais crescentes na Amazônia, poderíamos esperar um proporcional desequilibrio na vazante dos rios da região. Schubart (1977) verificou que o latossolo amarelo pesado - como o estudado para este trabalho - compacta-se muito rapidamente, e que a porosidade normal sob floresta é mantida pelas raízes e pequenos animais do solo. De fato verificou- 
se que em muitos pontos onde a água se infil trava mais rapidamente havia cupins. Portan to seria desaconselhável qualquer manejo in. cluindo inseticidas nas culturas, pois os cupins morreriam e, conseqüentemente, o solo se tornaria mais compacto. Harris (1961: 79) observou que Odontotermes badius, numa cultura de café no Kênia, pela atividade de escavação. transporta as folhas caídas para dentro do solo e assim aumenta a aeração superficial e cio subsolo, favorecendo inclusive a penetração de raízes.

Dos cupins coletados na Fazenda Aruanä, o gênero de maior diversidade de formas e mais freqüente foi Nasutitermes, encontrado em todos os habitats. No Mato Grosso, Centro Oeste brasileiro, eles são também encontrados em todos os tipos de ambientes, sendo €specializados numa grande variedade de $\mathrm{ni}$ nhos (Mathews, 1977). Na Amazônia Central, possivelmente Nasutitermes são os cupins mais importantes na decomposição da madeira morta, pois seus ninhos são muito freqüentes sobre troncos secos, tocos, raizes expostas e os cupins podem ser encontrados também no interior dessas estruturas.

Muitos cupins não podem viver em áreas desflorestadas, onde lhes faltam árvores para suporte dos ninhos e alimentação (Wood. 1975). Neste trabalho, porém, não se pode provar que grupos estariam nesta categoria, pois a diversidade parecia ser muito grande e os dados não foram suficientes, inclusive porque os cupins não puderam ser identificados a nível de espécies. Acredita-se que a alteração dos elementos microclimáticos, alguns dos quais relatados aqui, teria algum efeito na distribuição de certos grupos e possivelmente €ssa seria uma das causas da maior freqüência de Nasutitermes nas áreas desmatadas. O fato de se ter observado mais cupins no solo de habitats menos florestados provavelmente se deve à grande fonte de celulose das árvores e raízes mortas, já que os Isoptera são na maioria xilófagos. A capoeira, que tinha vegetação intermediária entre a floresta e a pastagem, apresentou maior densidade de cupins no solo. É possivel que isso se deva às modificações menos rigorosas do microclima em relação à pastagem, pois a quantidade de de- tritos e troncos mortos parecia ser semelhante em ambos os ambientes. Se isso for verdade, seria aconselhável a formaçāo de pastagens mistas, com faixas de capoeiras ou de árvores primárias alternadas com faixas de gramíneas e não a formação de grandes áreas contínuas, como é comum se ver na regiāo. Os cupins em pastagens são importantes na decomposição dos detritos. Como existem geralmente muitos troncos de árvores derrubadas, eles auxiliam a reciclagem dos nutrien. tes no ecossistema, lenta e regularmente. Neste caso, o fogo não parece ser apropriado para a manutenção de pastagens, pois os troncos secos queimados liberam os nutrientes de uma só vez, em forma de cinzas, que podem ser lixiviadas e postas fora do alcance do sistema radicular das culturas, além dos cupins logicamente morrerem.

Em áreas de pastoreio na Austrália, Ferrar $\&$ Watson (1970) convenceram-se que os cupins têm papel muito importante na remoçẫo de partículas de fezes secas para dentro do solo e na sua decomposição, cujas partes fibrosas são aproveitadas como alimento. Na Amazônia Central, parece que os cupins não têri muita preferência pelos dejetos animais, pois foram encontradas poucas fezes com cupins e a diversidade destes também foi pequena. Dantas (1978), fazendo observações na mesma área, encontrou grandes quantidades de escarabeídeos nas fezes de gado, e esses coleópteros, como se sabe, constituem um grupo de grande importância na dispersão dos dejetos animais nas áreas tropicais. Na Austrália, os escarabeídeos indigenas são representados por poucas espécies adaptadas aos excrementos de marsupiais e de pássaros autóctones (Dajoz, 1970), e com a introdução do gado bovino e ovino pelo homem, os referidos coleópteros não ampliaram sua atividade coprofilica até os excrementos desses animais domésticos. Os cupins, talvez não encontrando competidores, apossaram-se do novo nicho. $\mathrm{Na}$ Amazônia Central, tal competição parece ocorrer, e os cupins seriam os menos favorecidos.

Na Amazônia Central, os dois maiores grupos de animais, em biomassa, são formigas c cupins (Fittkau \& Klinge, 1973). Dentre os predadores de cupins, parece que as formigas são 
o principal grupo. Portanto o fluxo de energia, partindo da decomposição da madeira, por cupins, e de outras estruturas ricas em celulose, passaria pelas formigas. Assim, tornarse-iam bastante interessantes mais estudos sobre as interrelações de cupins e formigas, a fim de se ter melhores informações sobre o papel ecológico desses dois grandes grupos de insetos da Amazônia.

\section{Agradecrmentos}

Ao Conselho Nacional de Desenvolvimento Científico e Tecnológico (CNPq), pela concessão da bolsa de estudo; Instituto Nacional de Pesquisas da Amazônia (INPA)/Universidade do Amazonas, pelo apoio técnico-científico para a realização deste trabalho; Prof. Dr. Warwick E. Kerr, Diretor do INPA, pela oportunidade que me deu de fazer o curso de Mestrado em Ecologia nesse Instituto; Prof. Dr. Herbert O. R. Schubart, coordenador do Curso de Pós-Graduação em Ecologia e meu orientador de tese, pelo encorajamento, apoio e sugestões constantes, essenciais para a realiza. ção do presente trabalho; Dr. Renato L. Araújo, pela identificação dos cupins, pelas sugestões e grande incentivo; Drs. Cincinnato Goncalves, Norman Penny e William Overal, pela identificação das formigas; Mário Dantas, M. Sc., pelo companheirismo nos trabalhos de campo (com quem fiz parte das pesquisas) e excelentes idéias para melhorar o presente trabalho: Miguel Petrere Jr., M. Sc., pela orientação na análise estatística dos dados: Dr. Sérgio Vergueiro, pela permissão de realizar pesquisas em sua propriedade; Sr. Nilamon Camargo Penteado, gerente da Fazenda. pela hospitalidade e ajuda em alguns traba thos de campo, e demais pessoas que contribuíram, direta ou indiretamente, para a realização deste trabalho.

\section{SUMMARY}

Distribution and diversity of termites were studied in areas of primary forest, capoeira (secondary forest) and pastûre in Central Amazonia, near Manaus, Amazonas State. Soil humidity, soil compactation (infiltration rate of water in the soil), and soil and air temperatures were measured to establish relationships with the termite distribution. With approximately the same amount of collecting in each of the three habitats, it was found that most of the genera were distributed in the three environments. Some genera were sorted into species. Nasutitermes was the most common genus, with the greatest number of species. and was most frequent in pasture. The total number of nests was also higher in the pasture than in the primary forest. Termites in the soil can reach almost a meter in depth and their abundance was greatest in capoeira, fallowed by pasture and lastly primary forrest. The infiltration of water in the soil and the soil humidity diminished with deforestation. The diurnal range of soil and air temperatures was greater in pasture than in primary forest. The lack of vegetation and its effects on the microclimate could be responsible for the distribution of some Isoptera groups. Several species of ants were found to be predators of termites, mainly when nests were opened for collecting.

\section{BIBLIOGRAFIA}

ALLeN, S.E.
1974 - Chemical Analysis of Ecological Materials Blackwell Sci. Publ.. Oxford. Seção 1, p. 21-22.

ARAuJo, R.L.
1977 - Catálogo dos Isoptera do Novo Mundo. Rio de Janeiro, Academia Brasileira de Ciências. $92 \mathrm{p}$.

ВоDот, $\mathrm{P}$.

1967 - Étude écologique des termites des savanes de basse Cote-D'Ivoire. Insectes Sociaux, 14 (3): 229-258.

Discz, R.

1970 - Des animaux qui fertilisent les sols. Science Progrès Découverte, N. ${ }^{\circ}$ 3417: 12-18.

Dintas, M.
1978 - Pastagens da Amazônia Central: Ecologia e fauna do solo. Tese de M. Sc., INPA/ Univ. do Amazonas, $95 \mathrm{p}$.

EMERSON, A.E,

1936 - Distribution of termites. Science, N. York, 83: $410-411$.

Ferrar, P. \& WATSON, T.A.L.

1970 - Termites associated with dung in Australia. J. Aust. Entomol. Soc. 9 (2): 100-102.

FittKau, E.J. \& Klinge, H.

1973 - On biomass and trophic structure of the Central Amazonian rain forest ecosystem. Biotropica, 5 (1): 2-14. 
GARCIA, M.L. \& BeCKER, G.

1975 - Influence of temperature on the development of incipient colonies of Nasutitermes nigriceps (Haldemann) Z. Angew. Entomol., 79 (3): 291-300.

HARRIS, W.V.

1961 - Termites: Their recognition and control. London, Logmans, Green \& Co. Ltd. $186 \mathrm{p}$.

1966 - The role of termites in tropical forest. In. sectes Soc., 13 (4): 255-265.

HESSE, P.R.

1955 - A chemical and physical study of the soils of termite mounds in East Africa. J. Ecol., 43: $449-461$.

Instituto de Pesquisas e Experimentação Agropecuíria DO NORTE (IPEAN)

1969 - Os solos da Área Manaus-Tacoatiara. Manaus, Secretaria de Estado de Produçāo, $117 \mathrm{p}$.

KLINGE, H, \& RODRIgUes, W.A.

1968 - Litter production in an area of amazonian terra firme. Part I. Litter-fall, organic carbon and total nitrogen contents of Litter. Amazoniana, 1 (4): 287-302.

LEE, E. \& WoOD, T.G.

1971 - Termites and soils. London, Academic Press. $251 \mathrm{p}$.

Longman, K.A. \& Jeník, J.

1974 - Tropical forest and its environment. London, Longman Group Limited. 196 p.

MACFADYEN, A.

1953 - Notes on methods for the extraction of small soil arthropods. J. Anim. Ecol., 22: 65-77.

MAthews, A.G.A.

1977 - Studies on termites from the Mato Grosso State, Brazil. Pio de Janeiro, Academia Brasileira de Ciências. 267 p.

MAтsumoto, $\mathrm{T}$.

1976 - The role of termites in an equatorial rain forest ecosystem of West Malaysia: Oecologia (Barl.). 22 (2): 153-178.

RIBEIRO, M.N.G.

1976 - Aspectos climatológicos de Manaus. Acta Amazônica, 6 (2): 229-233.
Rodrigues, W.A.

1967 - Inventário florestal piloto ao longo da estrada Manaus-Itacoatiara, Estado do Amazonas: dados preliminares. In: HELMAN, Lent (Editor). Atas do Simpósio sobre a Biota Amazônica 7 Botânica : 257-267. Conselho de Pesquisas. Rio de Janeiro.

SANDS, W.A.

1965 - Termite distribution in man-modified habitats in West Africa, with special reference to species segretation in the genus Trinervitermes (Isoptera, Termitidae, Nasutiterminae). J. Anim. Ecol., 34: 557-571.

SсніміDт, C.J.

1947 - O clima da Amazônia. Rev. Brasileira de Geografia, 4 (3): 1-33

SCHUBART, H.O.R.

1977 - Critérios ecológicos para o desenvolvimento agrícola das terras-firmes da Amazônia. Acta Amazônica, 7 (4): 559-567.

SOKAL, R.R. \& ROHLF, F.J.

1969 - Biometry. San Francisco, W. H. Freeman and Company, $776 \mathrm{p}$.

USHER, M.B.

1975 - Studies on a wood - feeding termite community in Ghana, West Africa. Biotropica, 7 (4): $217-233$.

Villela, S.M. \& Mattcs, A.

1975 - Hidrologia Aplicada, São Paulo, Mc. Graw. Hill do Brasil. 245 p.

WHEELER, W.M

1936 - Ecological relations of Ponerine and other ants to termites. Proc. Amer. Acad. Arts. Sci., 71 (3): 159-243.

WCOD, T.G.

1975 - The effects of clearing and grazing on the termite fauna (Isoptera) of Tropical savannas and woodiands. In: VANER, J. - Progress in soil Zoology. Prague, Academia. p. $409-418$.

ZAR, J.H

1974 - Biostatistical Analysis. London, PrenticeHall Internacional. $620 \mathrm{p}$.

(Aceito para publicação em 04/04/79) 